\title{
Acute Renal Failure with Selective Medullary Injury in the Rat
}

\author{
S. N. Heyman, M. Brezis, C. A. Reubinoff, Z. Greenfeld, C. Lechene, F. H. Epstein, and S. Rosen \\ Department of Medicine, Hadassah University Hospital, Mount Scopus, Jerusalem, Israel; Charles A. Dana Research Institute, \\ Departments of Medicine and Pathology, Harvard Medical School and Beth Israel Hospital, Boston, Massachusetts 02115; \\ National Electron Probe Resource for Analysis of Cells, and Laboratory of Cellular Physiology, Harvard Medical School \\ and Brigham \& Women's Hospital, Boston, Massachusetts 02115
}

\begin{abstract}
Since human acute renal failure (ARF) is frequently the result of multiple rather than single insults, we used a combination of treatments to induce ARF in rats. Uninephrectomized, salt-depleted rats injected with indomethacin developed ARF after administration of radiocontrast. After $24 \mathrm{~h}$, the plasma creatine rose from $103 \pm 3$ to $211 \pm 22 \mu \mathrm{mol} / \mathrm{liter}$ (mean $\pm \mathrm{SE}$ ) and the creatinine clearance dropped from $0.7 \pm 0.1$ to $0.2 \pm 0.04$ $\mathrm{ml} / \mathrm{min}(P<0.001)$. Severe injury was confined to the outer medulla and comprised necrosis of medullary thick ascending limbs (mTALs), tubular collapse, and casts. Other nephron segments were free of damage except for the proximal convoluted tubules which showed vacuole formation originating from lateral limiting membranes that resembled changes reported in human contrast nephropathy. Cell damage to mTALs included mitochondrial swelling, nuclear pyknosis, and cytoplasmic disruption with superimposed calcification; these changes were most severe in the deepest areas of the outer medulla, away from vasa recta in zones remote from oxygen supply. The fraction of mTALs with severe damage was $30 \pm 7 \%$ (range 2-68) and the extent of injury was correlated with a rise in plasma creatinine $(r=0.8, P<0.001)$. Thus, the nature of mTAL injury was similar to the selective lesions observed in isolated kidneys perfused with cell-free medium and was shown to derive from an imbalance between high oxygen demand by actively transporting mTALs and the meager oxygen supply to the renal medulla.

Combined multiple renal insults in the rat produce ARF that resembles the clinical syndrome of contrast nephropathy and is characterized by selective mTAL injury conditioned by medullary hypoxia.
\end{abstract}

\section{Introduction}

The kidney may be particularly vulnerable to ischemia because of the precarious oxygenation of the renal medulla (1). This notion has originated from observations of selective hypoxic injury to medullary thick ascending limbs (mTAL) ${ }^{1}$ in

Address all correspondence to Dr. M. Brezis, Department of Medicine, Hadassah University Hospital, Mount Scopus, Jerusalem, POB 24035, Israel.

Received for publication 27 July 1987 and in revised form 14 December 1987.

1. Abbreviations used in this paper: ARF, acute renal failure; CM, contrast medium; INDO, indomethacin treatment; mTAL, medullary thick ascending limb; SD, salt depletion; UNK, uninephrectomy.

J. Clin. Invest.

(C) The American Society for Clinical Investigation, Inc. $0021-9738 / 88 / 08 / 0401 / 12 \$ 2.00$

Volume 82, August 1988, 401-412 isolated rat kidneys perfused with cell-free medium (2). Although identical lesions have on occasion been observed after hemorrhagic hypotension in the whole animal $(1,3)$, their occurrence and relationship to kidney dysfunction has been inconsistent. The present work is an attempt to produce and observe selective injury to mTALs in vivo.

The experimental design was based on the following premises. (a) Single insults of the type described here have not produced acute renal failure (ARF) in animals. (b) The combination of multiple renal insults may more closely resemble clinical ARF since in humans several predisposing factors are frequently involved $(4,5)$. (c) Measures shown to amplify mTAL injury in the isolated perfused kidney are likely to aggravate medullary hypoxia and to predispose the kidney to medullary damage in vivo.

Contrast media frequently used for radiological studies in man are recognized as a common cause of $\operatorname{ARF}(6)$. The mechanism of kidney injury remains unclear, although the coexistence of underlying renal disease or impairment of renal function appears to predispose patients to renal failure after the administration of contrast agents $(7,8)$. The scarcity of adequate animal models has seriously impeded progress in the understanding and prevention of this iatrogenic disorder.

In the present study in rats, we have used multiple, modest renal insults that did not induce major renal injury when applied separately, but in combination produced a form of ARF that resembles the clinical syndrome of contrast nephropathy. Observations in vivo and in vitro disclosed predominant injury in the renal medulla, which suggests a role for medullary hypoxia in this model of ARF.

\section{Methods}

In vivo studies. Male rats of the Sabra strain (Wistar-derived) from the Hebrew University, weighing 260-380 g, were used for all experiments. On day 0 , under anesthesia with pentobarbital $(50 \mathrm{mg} / \mathrm{kg}$ body weight, i.p.), the femoral artery was cannulated, using a polyethylene catheter (PE 50; Clay-Adams, Parsippany, NJ) which exited through the skin in the back of the neck to allow daily blood sampling and the injection of contrast agents. From $1 \mathrm{~d}$ before this instrumentation and for 3-4 $d$ thereafter, the rats were kept in Nalgene metabolic cages (Nalge Co., Rochester, NY), fed on a standard rat chow, and allowed free access to water except for the day of the insult. Daily collections of urine $(24 \mathrm{~h})$ and blood were performed for the determination of creatinine and electrolytes using standard laboratory techniques. In a limited number of rats, an inulin solution, containing $20 \mathrm{mg} / \mathrm{ml}$ cold inulin and $0.8 \mu \mathrm{Ci} / \mathrm{ml}$ radioactive $\left[{ }^{3} \mathrm{H}\right]$ inulin, was infused at the rate of 0.5 $\mathrm{ml} / \mathrm{h}$ for $24 \mathrm{~h}$ before, and $24 \mathrm{~h}$ after, the acute insults for the determination of inulin clearance. The latter was calculated from a 24-h urine collection and from an average of two plasma levels (obtained after the beginning and at the end of the collection).

The contrast material. Sodium iothalamate, $80 \%$ (Angio-Conray; Mallinckrodt, Inc., St. Louis, MO) was injected through the arterial cannula over $\sim 2 \mathrm{~min}$, at the dosage of $6 \mathrm{ml} / \mathrm{kg}$ body weight (or $2.9 \mathrm{~g}$ of 
organically bound iodine/kg of body weight). As suggested by others ( 7 , 9) and confirmed in our own preliminary observations (unpublished), although high doses of radiocontrast media administered to normal animals may induce transient renal dysfunction, a prolonged syndrome of ARF is rarely produced. To increase the likelihood of a renal injury, rats were preconditioned, before the injection of contrast, by one or more of the following treatments.

Chronic salt depletion. Because it has been suggested as a risk factor for contrast nephropathy (10), salt depletion was induced in rats before their exposure to the contrast agent. After four daily injections of furosemide $(2 \mathrm{mg} / \mathrm{kg}$ ), rats were fed exclusively on boiled rice (sodium content $2 \mathrm{mg} / 100 \mathrm{~g}$ ) for a period of $7 \mathrm{~d}$ until the injection of radiocontrast material. At this time the daily urinary excretion of sodium was $278 \pm 32 \mu$ eq $($ mean \pm SE) compared with $1,118 \pm 105 \mu$ eq $(P<0.001)$ in rats not subjected to this treatment.

Acute inhibition of prostaglandin synthesis by indomethacin. Because inhibition of prostaglandin synthesis may predispose kidneys to ARF (11) and medullary hypoxic injury (12), it was attempted as a means to amplify any renal insult from radiocontrast media. Indomethacin (Sigma Chemical Co., St. Louis, MO) was dissolved in phosphate buffer ( $\mathrm{pH}$ 8.0) and administered $1 \mathrm{~h}$ before the injection of contrast as a single intravenous injection $(10 \mathrm{mg} / \mathrm{kg})$. This dose was chosen because it was found to produce an effective suppression of $\mathrm{PGE}_{2}$ synthesis with minimal renal dysfunction in normal rats (13).

Reduction of renal mass by uninephrectomy. Because chronic renal failure appears in itself to be a risk factor for the development of contrast nephropathy $(6,7)$ and because prior uninephrectomy augments mTAL injury during isolated perfusion of the remnant kidney (14), chronic reduction of the functional renal mass was also attempted to increase the susceptibility of the rats to renal injury from radiocontrast material. Under light ether anesthesia, the left kidney was removed after ligation of its pedicle, 3-5 wk before the exposure of the animal to contrast.

Preliminary observations. Multiple combinations of insults were initially tested in animals with two kidneys. As shown in Fig. 1, renal dysfunction appeared more pronounced when the rats were exposed to the combination of salt depletion, indomethacin, and contrast material. Under these circumstances, renal morphology disclosed focal tubular necrosis in the inner stripe of the outer medulla, involving thick ascending limbs of Henle's loop. In an attempt to amplify this injury and make it more consistent, the combinations of insults were performed in rats after uninephrectomy as follows.

Experimental groups. Group UNK, SD, CM $(n=6)$ : uninephrectomized, salt-depleted rats were injected with contrast material. Group UNK, INDO, CM $(n=6)$ : uninephrectomized rats pretreated with indomethacin were injected with contrast material. Group UNK, SD, INDO, CM $(n=10)$ : uninephrectomized, salt-depleted rats pretreated with indomethacin were injected with contrast material. Group UNK, $\mathrm{SD}$, INDO $(n=5)$ : uninephrectomized, salt-depleted rats were injected with indomethacin.

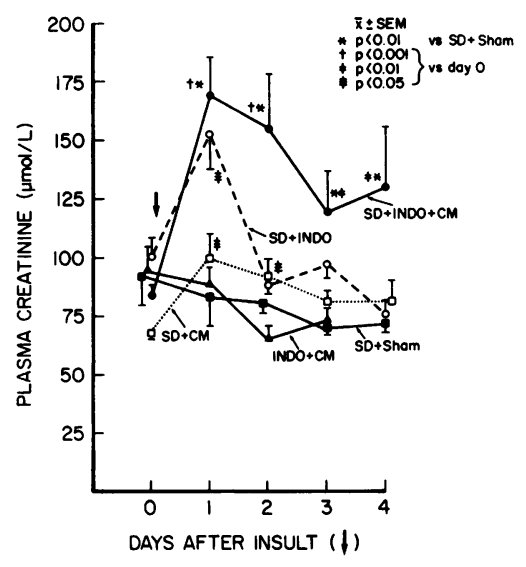

Figure 1. Plasma creat combined insult in preliminary observations in rats with two kidneys. $S D$, salt depletion; INDO, indomethacin; $C M$, contrast medium; Sham, sham instrumentation.
Morphological studies. The functional studies were usually terminated $24 \mathrm{~h}$ after the acute insults and the histology of all kidneys were examined. To observe the earliest occurrence of thick ascending limb necrosis after acute insults, seven additional rats treated as in group UNK, SD, INDO, CM were killed at early time periods ( $70 \mathrm{~min}, 1 ; 80$ min, $1 ; 120 \mathrm{~min}, 5)$ and their kidneys were examined.

Under anesthesia, the right kidney was perfused after cannulation of the renal artery at a pressure of $140 \mathrm{mmHg}$, using first a saline rinse of $20 \mathrm{ml}$ and then a solution of $1.25 \%$ glutaraldehyde (E. Merck, Darmstadt, FRG) in $0.1 \mathrm{M}$ phosphate buffer (pH 7.4, osmolality 300 mosmol/ $\mathrm{kg} \mathrm{H}_{2} \mathrm{O}$ ). The sections were postfixed in buffered $2 \% \mathrm{OsO}_{4}$, dehydrated, and embedded in an araldite-Epon 812 mixture. Large (3 $\times 3 \mathrm{~mm}$ ) sections were cut, which contained cortex and outer medulla. The sections were examined by light microscopy. Analysis of injury was completed in a blinded fashion by Dr. Rosen as previously described $(2,15)$. Selected blocks were examined by electron microscopy. The electron microprobe studies were done using the National Electron Probe Resource for analysis of cells (C. Lechene).

In the inner stripe of the outer medulla, abnormal mTALs were counted and expressed as the percentage of the total number of tubules in three zones: most superficial, adjacent to the outer stripe (region A), midzone (region B), and deepermost, adjacent to the inner medulla (region $\mathrm{C}$ ). Because the great majority of findings was confined to regions $B$ and $C$, the proportion of $m$ TALs with injury presented in the results is the average for regions $B$ and $C$, unless otherwise indicated. It should be noted that when mTAL necrosis occurred in vivo, it usually predominated in either region B or C. Averaging B and C thus underestimates (by as much as $50 \%$ ) the number of nephrons with at least one focal lesion along the mTAL but it was used for simplicity.

Isolated kidney perfusions. Male Sabra rats, weighing 270-415 g, were used for all experiments. Isolated perfusion of the right kidney was performed according to the technique described by Ross et al. (16). Unless otherwise indicated, perfusate consisted of a Krebs-Ringer's Henseleit solution with BSA at a concentration of $6.7 \mathrm{~g} / 100 \mathrm{ml}$ and glucose at $5 \mathrm{mM}$, gassed with $5 \% \mathrm{CO}_{2}$ and $95 \% \mathrm{O}_{2}$ as in previous work $(2,15)$. Kidneys were perfused for $90 \mathrm{~min}$ before their fixation for histologic evaluation. The following experimental groups were studied.

Control perfusions $(n=10)$. Kidneys perfused with regular perfusion medium and no supplements.

Perfusions with contrast medium $(n=10)$. After $20 \mathrm{~min}$ of regular perfusion, sodium iothalamate (Angio-Conray) was added at once to the perfusate reservoir, at a final concentration of $25 \mathrm{mM}$.

Perfusions with indomethacin and contrast medium $(n=10)$. Indomethacin was injected intravenously $(5 \mathrm{mg} / \mathrm{kg}) 1 \mathrm{~h}$ before the start of the experiments and added to the perfusate at the concentration of $10^{-4} \mathrm{M}$, as previously described (12), to suppress $\mathrm{PGE}_{2}$ production effectively in this model. After 20 min of perfusion, sodium iothalamate was added as in the previous group.

Nonfiltering kidney $(n=6)$. Kidneys were perfused with a hyperoncotic medium (the albumin concentration was raised to $\sim 13 \mathrm{~g} / 100$ $\mathrm{ml}$ ) to stop glomerular filtration. After $20 \mathrm{~min}$ of perfusion, sodium iothalamate was added to the perfusate at the final concentration of $25 \mathrm{mM}$.

Perfusions with ouabain $(n=4)$. Kidneys were perfused with regular medium supplemented with ouabain $\left(10^{-3} \mathrm{M}\right)$ to inhibit active sodium transport. After 20 min of perfusion, sodium iothalamate was added as in the previous groups.

Perfusions with erythrocytes $(n=6)$. Kidneys were perfused with regular medium supplemented with rat blood as a source of erythrocytes at a final hematocrit of $9 \%$, as previously described (2). After 20 min of perfusion, sodium iothalamate was added as in the previous groups. (In three experiments, indomethacin was also added but since the results with and without indomethacin did not differ, these perfusions were pooled in a single group.)

Monitoring of renal function $(2,15)$ and quantitation of injury to the mTALs were performed as mentioned above, the morphological evaluation being done without knowledge of the experimental condi-

tions $(2,15)$. 
Table I. Plasma Creatinine and Creatinine Clearance before (Day 0) and after the Acute Insult(s) (Day 1) and Semiquantitative Morphological Observations on the mTAL (at the End of Day 1) in Experimental Groups In Vivo

\begin{tabular}{|c|c|c|c|c|c|c|}
\hline \multirow[b]{2}{*}{ Experimental group } & \multicolumn{2}{|c|}{ Plasma creatinine } & \multicolumn{2}{|c|}{ Creatinine clearance } & \multicolumn{2}{|c|}{ Proportion of mTALs } \\
\hline & Day $0^{*}$ & Day 1 & Day $0^{*}$ & Day 1 & With collapse & With necrosis \\
\hline & \multicolumn{2}{|c|}{ $\mu$ mol/liter } & \multicolumn{2}{|c|}{$\mathrm{ml} / \mathrm{min}$} & \multicolumn{2}{|c|}{$\%$} \\
\hline UNK, SD, CM $(n=6)$ & $107 \pm 14$ & $97 \pm 3$ & $0.71 \pm 0.29$ & $0.59 \pm 0.13$ & $60 \pm 14$ & 0 \\
\hline UNK, INDO, CM $(n=6)$ & $117 \pm 11$ & $133 \pm 14$ & ND & $0.46 \pm 0.06$ & $62 \pm 12$ & $9 \pm 3$ \\
\hline UNK, SD, INDO, CM $(n=10)$ & $103 \pm 3$ & $211 \pm 22^{\ddagger}$ & $0.73 \pm 0.06$ & $0.19 \pm 0.03^{\ddagger \S}$ & $33 \pm 8$ & $30 \pm 7$ \\
\hline UNK, SD, INDO $(n=5)$ & $101 \pm 12$ & $151 \pm 24$ & $0.77 \pm 0.26$ & $0.18 \pm 0.04$ & $26 \pm 16$ & $9 \pm 8$ \\
\hline
\end{tabular}

Comparisons between groups use the Bonferroni assumption. $\quad$ * Before the acute insults; ${ }^{\ddagger} P<0.001$ vs. value on day 0 in the same group; ${ }^{\S} P$ $<0.05$ vs. value on same day in the two previous groups.

Statistical analysis. Results are presented as mean \pm SE. Unpaired $t$ test was used unless otherwise indicated. For multiple comparisons of groups (Table I), Bonferroni's assumption was used. Linear and multiple regression analysis was used to correlate structural with functional observations. To determine the role of each insult in the development of renal injury, discriminant analysis was applied as described for the determination of risk factors in clinical ARF (4). The absence or the presence of an insult is defined as a binary variable (with the arbitrary respective values of 0 or 1). Stepwise logistic analysis (using multiple linear regressions) allows one to identify insults independently asso-
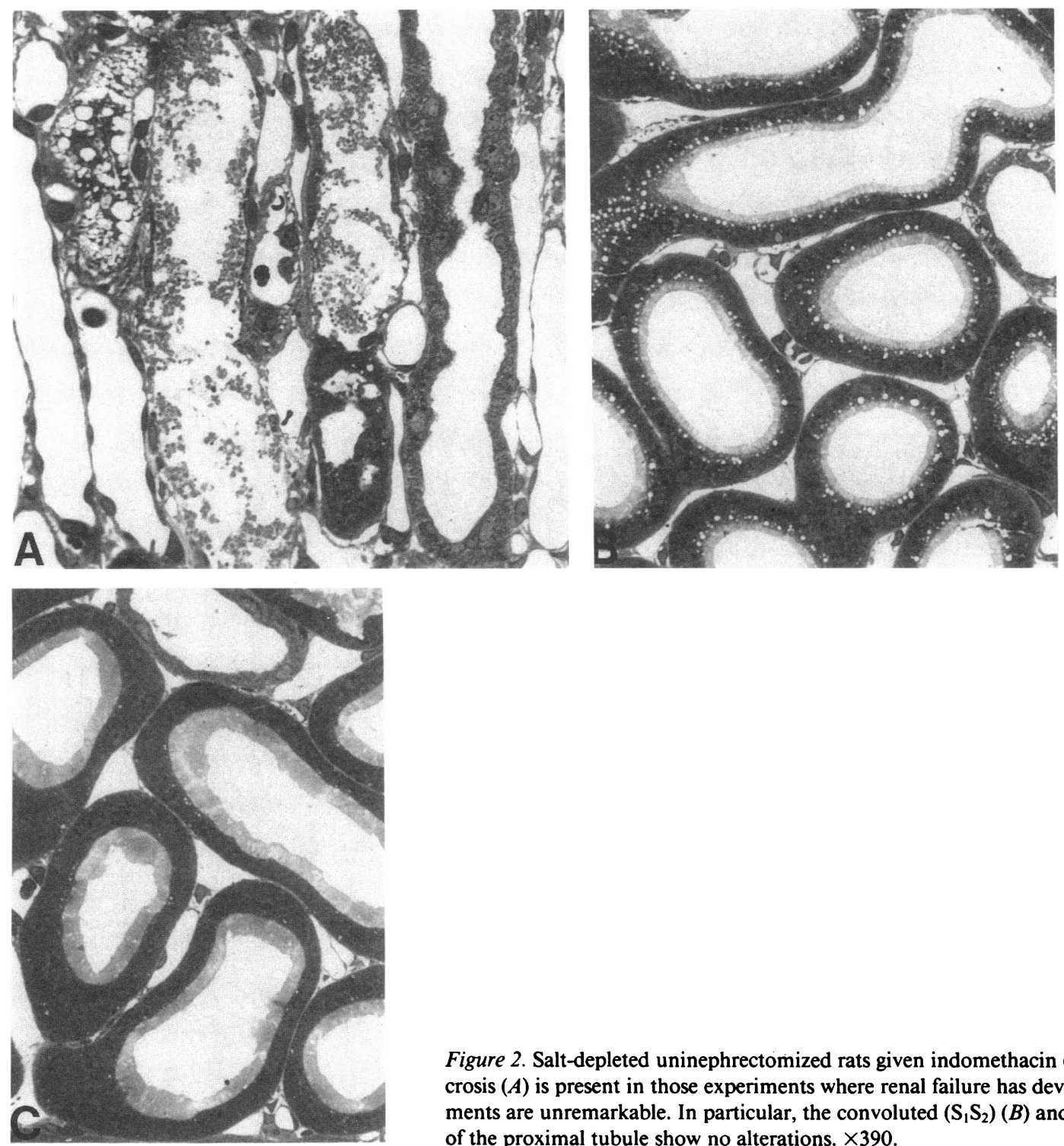

Figure 2. Salt-depleted uninephrectomized rats given indomethacin (killed at $24 \mathrm{~h}$ ). mTAL necrosis $(A)$ is present in those experiments where renal failure has developed. Other nephron segments are unremarkable. In particular, the convoluted $\left(\mathrm{S}_{1} \mathrm{~S}_{2}\right)(B)$ and pars recta $\left(\mathrm{S}_{3}\right)(C)$ portions of the proximal tubule show no alterations. $\times 390$. 

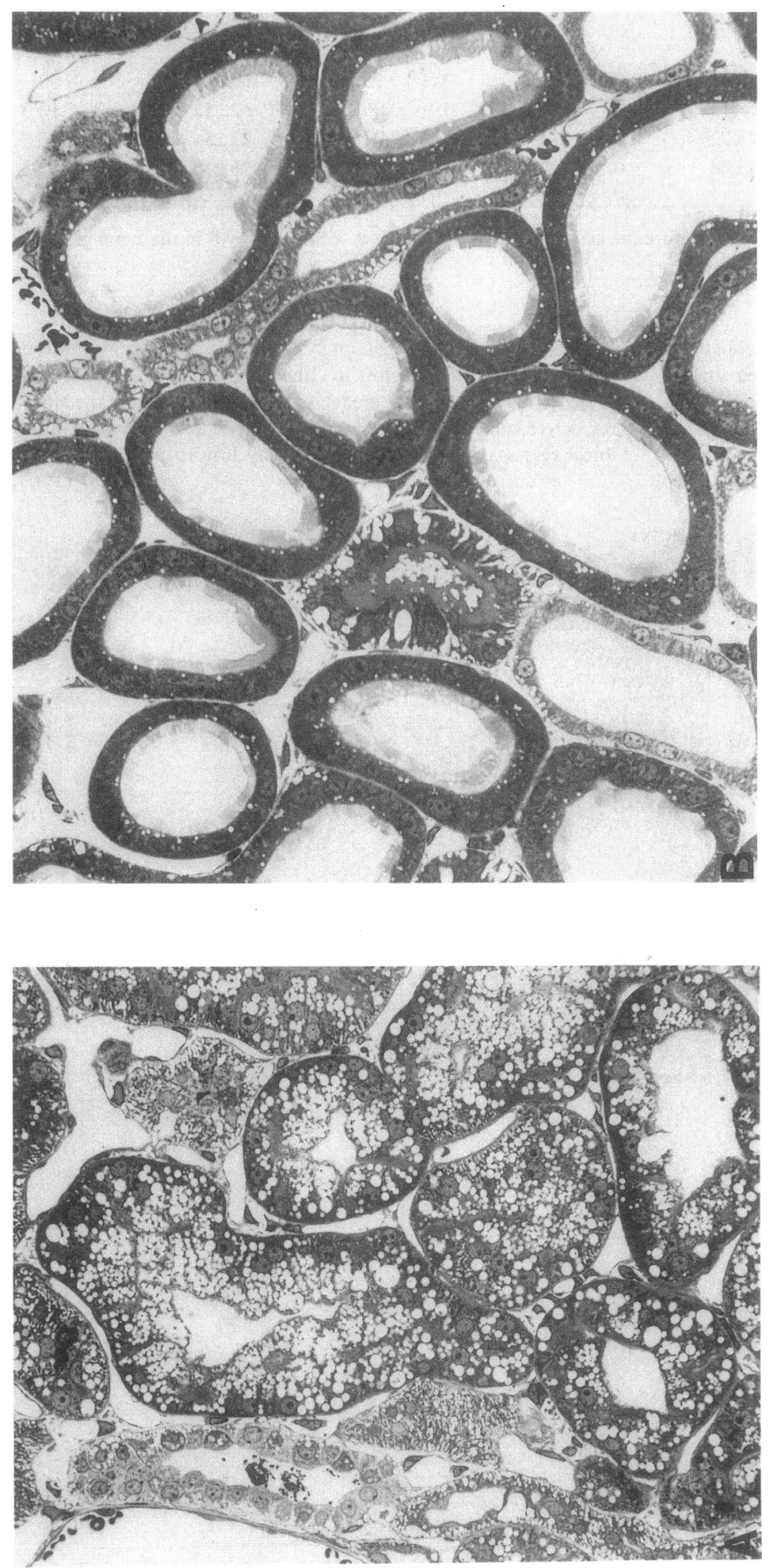
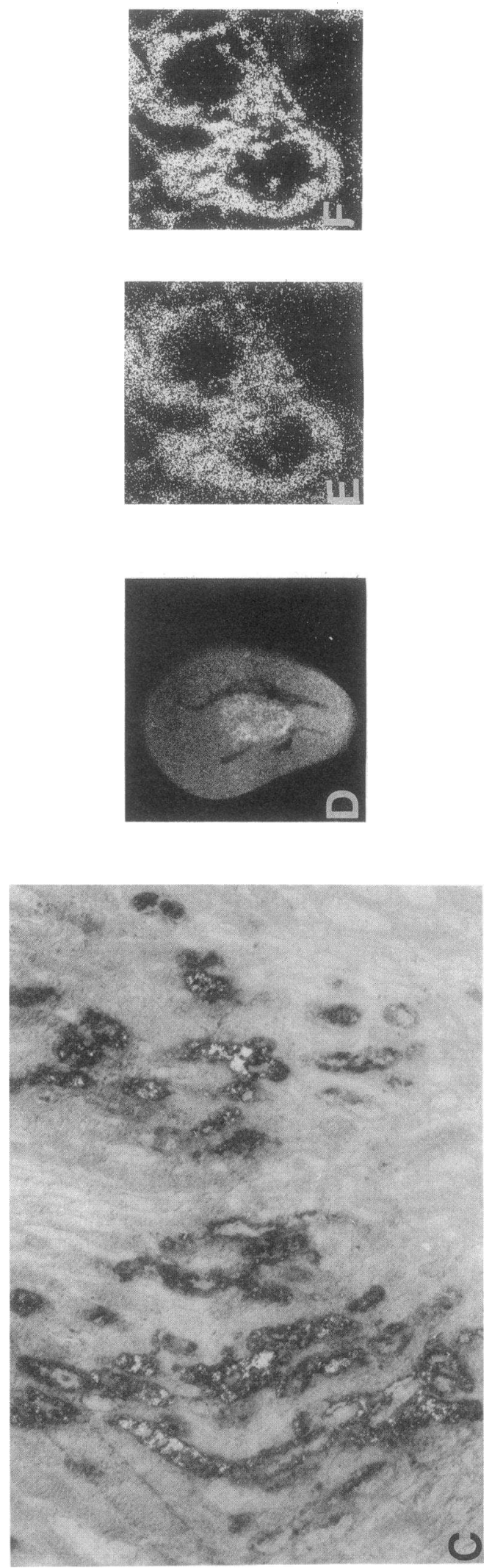


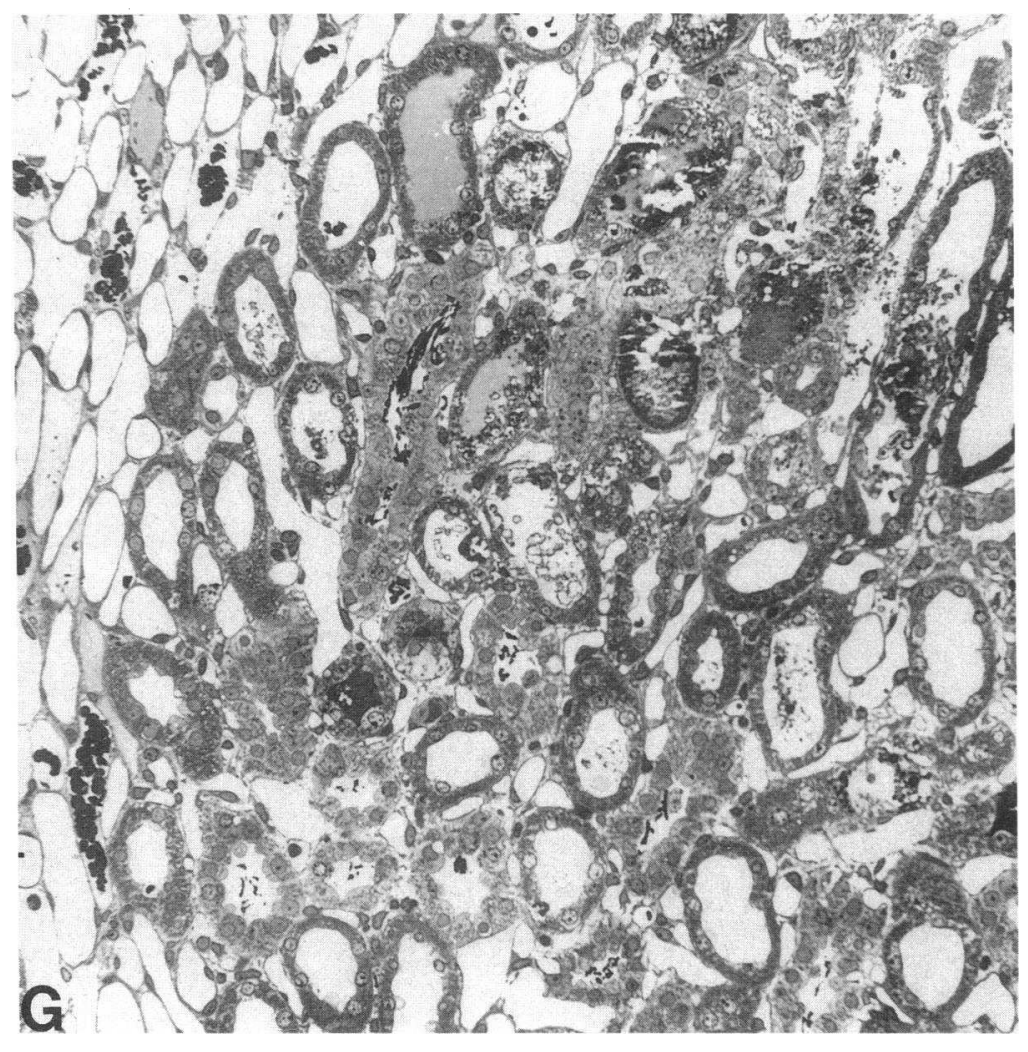

Figure 3. Salt-depleted uninephrectomized rats given indomethacin and sodium iothalamate (killed at $24 \mathrm{~h}$ ). Extensive vacuolar changes $(A)$ are noted in the proximal convoluted tubules $\left(\mathrm{S}_{1} \mathrm{~S}_{2}\right)$ but the pars recta $\left(\mathrm{S}_{3}\right)(B)$ is normal except for focal collapse. In the inner stripe of the outer medulla, polarizable material $(C)$ in the form of mTAL segments can be defined in unstained, uncoverslipped $1-\mu \mathrm{m}$ sections. Radiographs $(D)$ of $3-\mathrm{mm}$ sections of a whole kidney after perfusion fixation shows radio-opaque areas in this zone and electron probe analysis shows high concentrations of $\mathrm{Ca}(E)$ and $\mathrm{P}(F)$ in the mTAL. Stained plastic sections $(G)$ show mTAL necrosis in the central interbundle zones. $\times 430, A$ and $B$; $\times 100, C ; \times 330, E$ and $F ; \times 215, G$. ciated with the degree of renal injury and to define their relative contribution ( $\beta$ coefficient) in the model. Computations were performed with a computer package (CRUNCH; Crunch Software Corp., Oakland, CA).

\section{Results}

In vivo studies. As shown in Table $\mathrm{I}$, in the experimental groups receiving contrast material in association with salt depletion or indomethacin, only a moderate or nonexistent reduction in creatinine clearance was observed. When given in combination with both salt depletion and indomethacin, ARF invariably ensued, with an average doubling of the plasma creatinine (Table I). In five additional rats treated with this combination of insults, the clearance of inulin decreased from $1.6 \pm 0.2$ to $0.2 \pm 0.03 \mathrm{ml} / \mathrm{min}$ on the day before and the day after the acute insults, respectively $(P<0.001)$.

Morphology was remarkable for variable degrees of tubular collapse, focal mTAL necrosis, and occasional casts present in three of the four groups. In group UNK, SD, INDO, CM, however, all kidneys showed invariable and obvious cell necrosis in the mTALs (Table I). Necrosis of mTALs is illustrated in Fig. $2 A$ and contrasts with the preservation of the proximal tubule (Fig. $2 B$ and $C$ ). In fact, the cortex of these kidneys was remarkable only for convoluted proximal tubular-vacuolar changes which were conspicuous in four animals with worse renal failure (Fig. $3 A$ and $B$ ) (see below).

Additional morphological, radiographic, and electron microprobe observations. The medullary changes observed were centered in the deeper inner stripe. Without mounted coverslips, these areas polarized (Fig. $3 C$ ) and were shown by $\mathrm{x}$ rays (using standard mammographic techniques) to be radioopaque (Fig. $3 \mathrm{D}$ ). These areas were proved by electron probe analysis to contain high concentrations of calcium and phos- phorus and no detectable iodine (Fig. $3 E$ and $F$ ). Necrosis of mTALs was localized in the central interbundle regions, away from the vasa recta (Fig. $3 G$ ). The mTAL necrosis appeared in two phases. In the first, cell fragmentation, mitochondrial swelling, and nuclear pyknosis could be easily defined and the basal lamina was intact (Fig. $2 \dot{A}$ ). This injury was identical to that observed in the isolated kidney when erythrocytes are not included in the perfusate (2). In the second phase of mTAL injury, there was accumulation of electron-dense material (calcium) and the necrotic process extended into the interstitial tissues (Fig. $4 A-D$ ). Such zones were frequently fragmented by microtome sectioning. This necrotic calcification process was confined to group UNK, SD, INDO, CM and was present only at the usual 24-h period of examination. Of the animals treated as in this group but killed at earlier time periods, three of five showed very focal mTAL necrosis at 120 min after injection (Fig. 5). Other medullary elements were basically intact, though occasionally medullary thin descending limbs of long loops were necrotic. Focal vascular congestion and erythrocyte extravasation was present but the perfusion fixation made any quantification of this impossible. Erythrocytes were noted in tubular lumens as well.

In the first segments of the proximal tubule $\left(S_{1}-S_{2}\right)$, vacuolar changes were sometimes marked and distinguished from the usual endocytotic change beneath the brush border by encompassing the entire epithelial width (Figs. $3 A$ and 6). However, brush border, mitochondria, and nuclei appeared intact. Electron microscopy confirmed the basic integrity of these cells (Fig. 6). The nature of these vacuoles was best defined at the 120 -min time period where they seemed largely to originate from out-pouching of membranes of the lateral cellular interdigitations. Electron microprobe analyses failed to detect any iodine. 

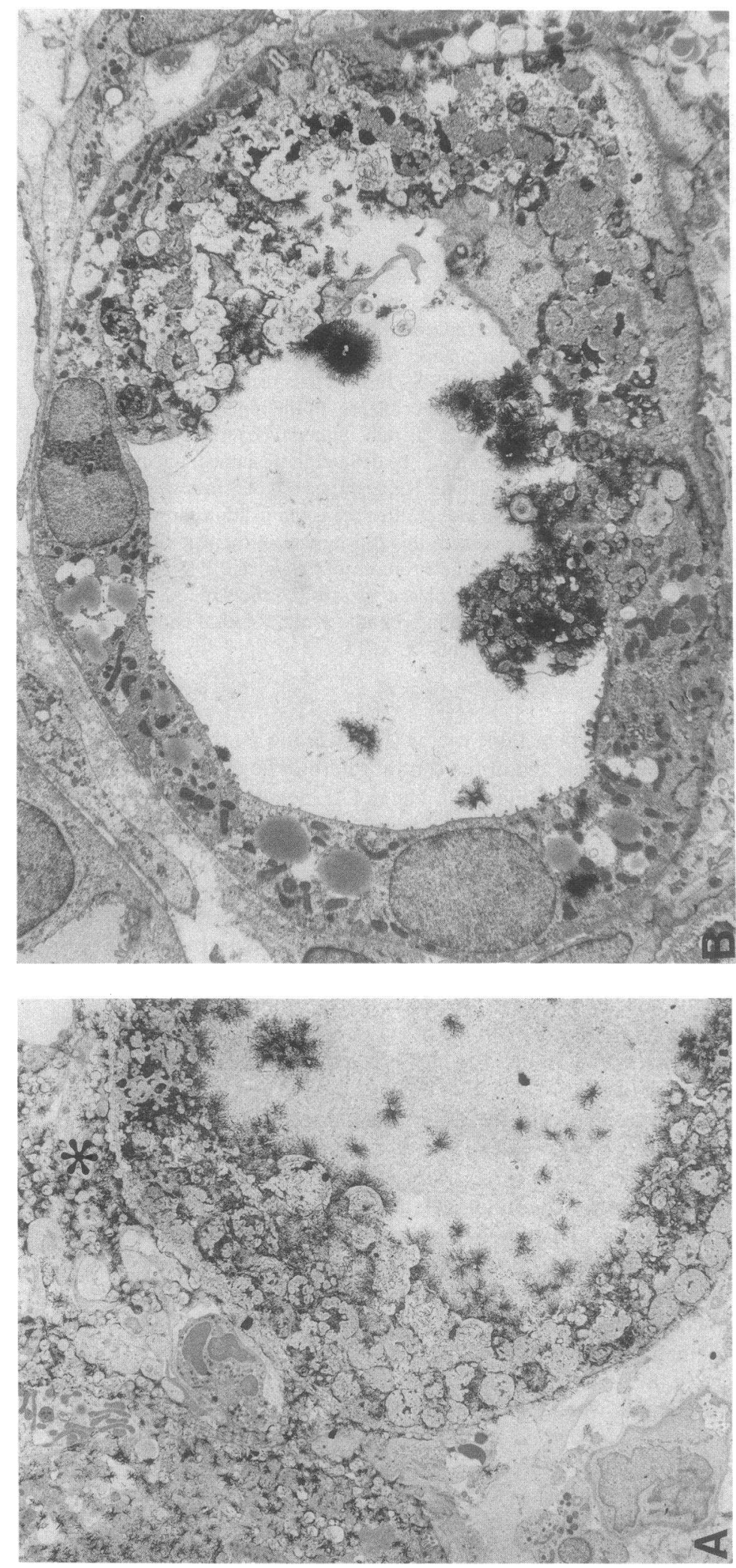
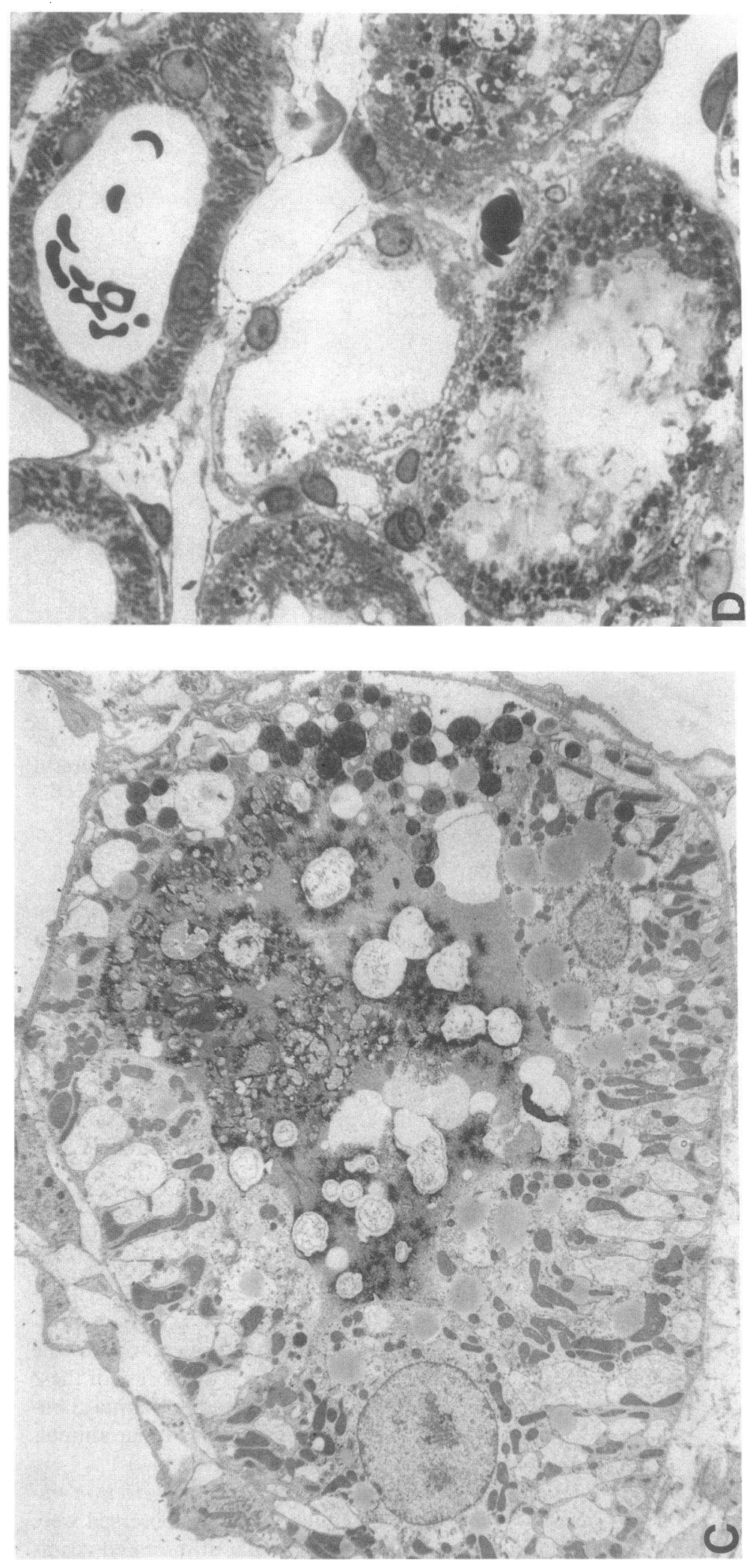


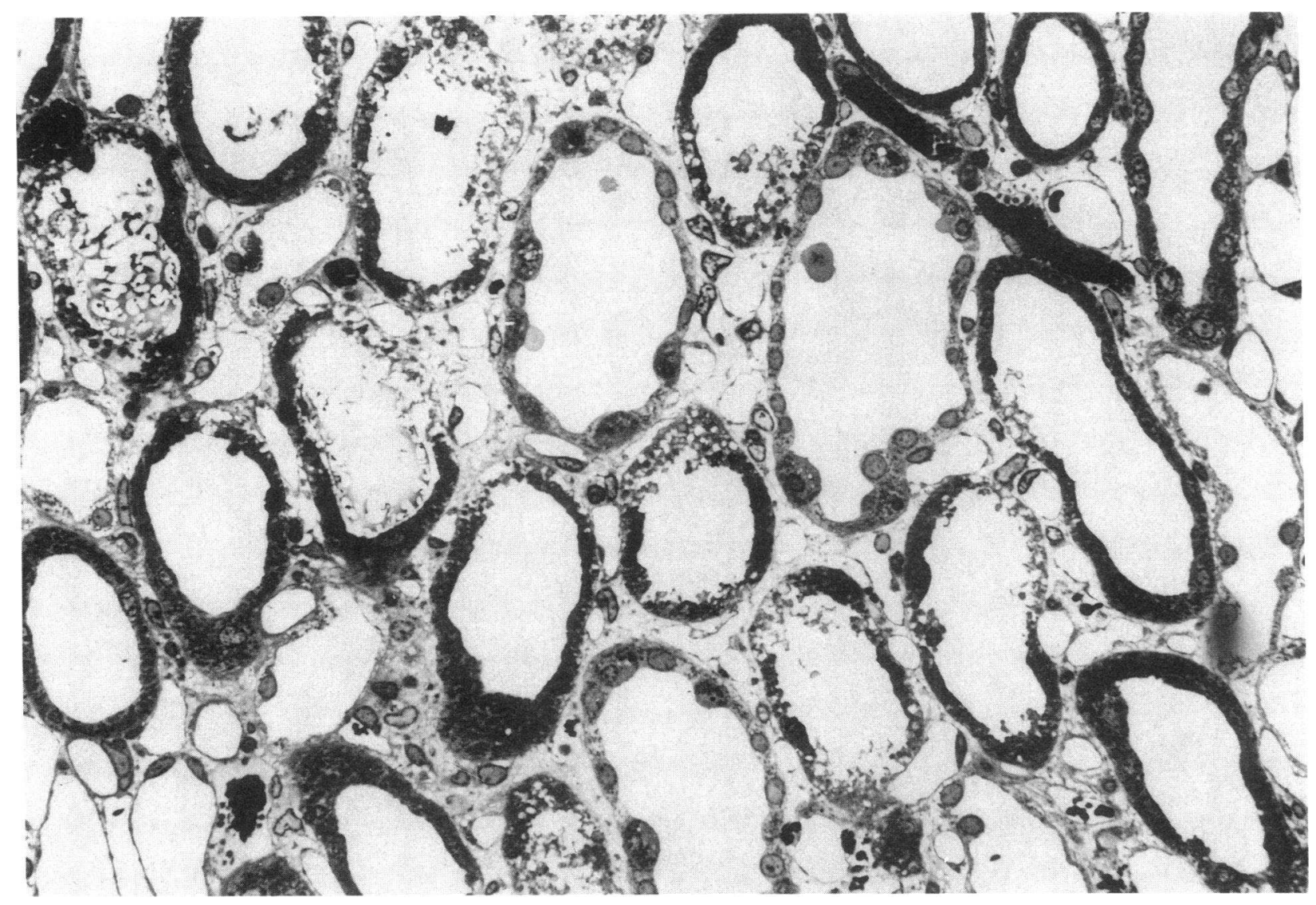

Figure 5. Salt-depleted uninephrectomized rats given indomethacin and sodium iothalamate (killed at 120 min). In this photograph the early development of the mTAL lesion can be recognized. Segmental tubular injury is present, characterized by membrane fragmentation and marked mitochondrial swelling. $\times \mathbf{4 4 0}$.

Correlation between structure and function. The proportions of mTALs involved with necrosis ranged from 2 to $68 \%$ (mean $30 \pm 7 \%$ ) and correlated with higher plasma creatinine on the day of the observation (Fig. 7). Multiple regression analyses of the correlations between functional and structural parameters from all experimental groups including the preliminary group of rats without uninephrectomy are shown in Table II. Plasma creatinine $1 \mathrm{~d}$ after the acute insult(s) was significantly correlated with both collapse and necrosis of mTALs $(r=+0.84, P<0.0001)$. Comparison of the regression slopes and partial correlation coefficients $r$ (Table II) indicated that necrosis of $\mathrm{mTALs}$ had a predominant effect on the rise in plasma creatinine, while collapse contributed a small but significant additional part. For identical plasma creatinine, the proportions of $\mathrm{mTALs}$ with collapse or necrosis were inversely correlated with eachother $(r=-0.78, P<0.0014)$.

Although correlation does not necessarily mean causal association, these data are compatible with the hypothesis that
mTAL collapse reflects a renal response to insults that is capable of preserving tubular integrity and kidney function. When mTAL necrosis replaces collapse, renal failure occurs.

Contribution of each insult to renal injury. The contribution of each of the multiple insults to the rise in plasma creatinine and to the development of mTAL necrosis was evaluated using a regression analysis shown in Table III. Although the effects of indomethacin appeared somewhat stronger than those of other treatments (compare $\beta$ coefficients in Table III), the presence of each insult was independently and significantly correlated with an increase in plasma creatinine and in percentage of mTALs necrosis. These data suggest a separate contribution from each insult to the renal injury, as a risk factor for the development of ARF in this model.

Additional in vivo observations. Myoclonus of the hindlimbs and the tail was consistently observed during the intraarterial injection of contrast material. Over the days after the arterial cannulation, ischemic changes were often noted in the
Figure 4. Salt-depleted uninephrectomized rats given indomethacin and sodium iothalamate (killed at $24 \mathrm{~h}$ ). Electron micrographs of mTALs show a loss of cellular detail and replacement by electronopaque material (presumably $\mathrm{CaPO}_{4}$ ), which delineates the swollen mitochondrial remnants. In $A$, both mTALs (upper left and right) are involved by this process and interstitial accumulation (*) of this material is seen as well. Micrograph $(B)$ shows a more segmental process (right) and the remaining mTAL cell elements show a decrease in mitochondrial mass, a loss of basilar membranes, and an accumu- lation of lipid droplets. In $C$, the electron-opaque material is seen within an mTAL tubular lumen. A segment of this tubule (right) shows mitochondrial swelling and opacification. The other portion of this tubule shows spreading of basilar membranes and accumulation of lipid droplets. These cellular changes are easily appreciated in $1-\mu \mathrm{m}$ plastic sections $(D)$. Note the normal mTAL epithelium of a tubule containing erythrocytes (upper right) compared with the tubule (lower left) with cast material, fragmented luminal membranes, and swollen dense mitochondria. $\times 2,000, A-C ; \times 760, D$. 

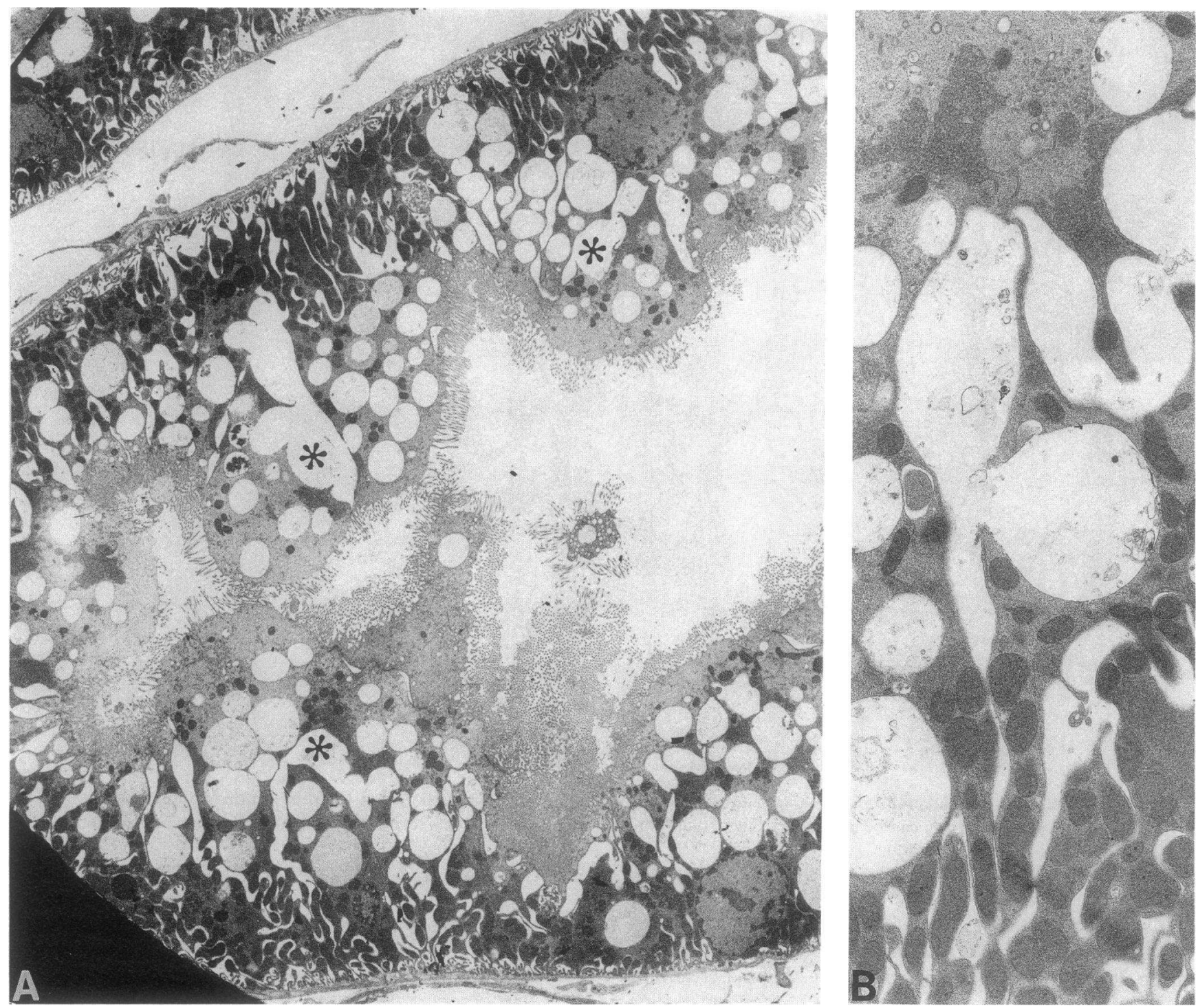

Figure 6. Salt-depleted uninephrectomized rats given indomethacin and sodium iothalamate (killed at $120 \mathrm{~min}$ ). Low-power electron micrograph shows the extensive vacuolar formation in this proximal convoluted tubule. Although some may be of endocytotic origin, connections between the basal lateral membranes and these vacuoles are readily apparent (*). At higher power, outpouchings from these membranes are evident. $\times 3,600, A ; \times 11,400, B$. leg, more pronounced in the animals injected with contrast. To evaluate a possible role for rhabdomyolysis in the pathogenesis of ARF in this model, plasma levels of creatinine phosphokinase were systematically measured $24 \mathrm{~h}$ after cannulation. The levels were elevated at $4,600 \pm 1,082,8,151 \pm 1,846$, $1,470 \pm 419$, and $1,249 \pm 519 \mathrm{IU} / \mathrm{ml}$ after SD, CM; SD, INDO, $\mathrm{CM}$; SD; and SD, INDO, respectively, compared with $115 \pm 27$ $(P<0.001)$ in a few rats treated by SD, INDO, and intravenous CM (no cannulation of the femoral artery) which also had milder renal injury. No correlation could be established, however, between the elevation of this enzyme and the severity of renal dysfunction, and the role of rhabdomyolysis in the induction of ARF in this model remains uncertain. Angiography performed in a few animals during the injection of radiocontrast could not demonstrate retrograde filling of the aorta to the renal arteries.

Because systemic hypotension has been reported to occasionally produce focal necrosis in the $\operatorname{mTALs}(1,3)$, in five rats exposed to SD, INDO, and CM, the blood pressure was recorded for $1 \mathrm{~h}$ after the injection of contrast, using a Statham transducer connected to the arterial cannula. Before the injection and at 2,10, and $60 \mathrm{~min}$ after the injection of contrast, the blood pressure was $105 \pm 4,114 \pm 6,89 \pm 5$, and $99 \pm 7 \mathrm{mmHg}$, respectively. In the group UNK, SD, INDO, CM the blood pressure measured at a similar time sequence was $100 \pm 6$, $98 \pm 3,100 \pm 4$, and $97 \pm 5(n=5)$. Severe hypotension or circulatory shock did not occur.

Studies in isolated perfused kidneys. Experiments in isolated perfused kidneys were conducted in parallel to the study in vivo in order to find measures capable of aggravating medullary hypoxia. Augmentation of mTAL injury in isolated kidneys by indomethacin (12) and by prior uninephrectomy (14) have been previously published. The present report deals with the effect of contrast material in the perfused kidney.

Hemodynamic observations. The addition of contrast to the perfusate of isolated kidneys produced marked biphasic 


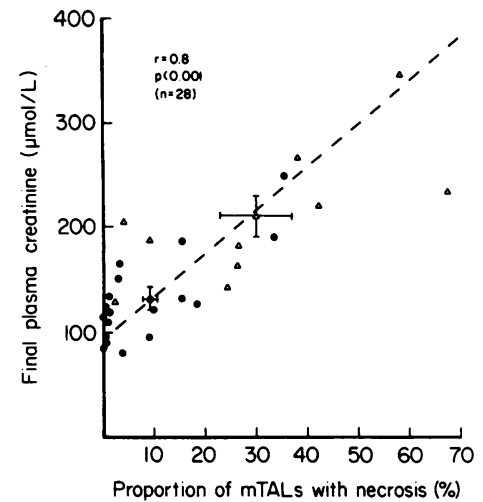

Proportion of mTALs with necrosis (\%)
Figure 7. Correlation between plasma creatinine (on the day after the insult) and the extent of $\mathrm{mTAL}$ necrosis in rats subjected to SD, INDO, and CM (closed circles) or UNK, SD, INDO, and CM (open triangles).

hemodynamic alterations beginning within 1-2 min that were similar to the changes described in vivo $(17,18)$. After the addition of contrast, an early renal vasodilatation, which lasted for a few seconds, was immediately followed by a slower vasoconstriction that was completed within 10 min and lasted until the end of the perfusion (see Table IV). These changes were not prevented by treatment with indomethacin but were blunted in nonfiltering kidneys. In the presence of ouabain, the vasoconstrictive phase was blunted.

Functional observations. As expected, the addition of hyperosmotic contrast material was followed by a profound natriuresis, which is indicated in Table IV by marked decreases in the tubular reabsorption of sodium. The administration of contrast, especially when combined with indomethacin treatment, led to a significant reduction in glomerular filtration rate. Indomethacin alone did not reduce renal function (12).

Morphological observations. As previously reported in detail (2), in isolated kidneys perfused with cell-free medium, medullary hypoxia causes a reproducible injury that is expressed by necrosis of approximately half of the medullary thick limbs in the deeper regions of the inner stripe (outer medulla). The effect of contrast medium upon this injury is summarized in Fig. 8. The administration of contrast, especially when combined with indomethacin treatment, led to significant increases in the extent of severe damage to the thick limbs. In nonfiltering kidneys perfused with iothalamate, necrosis of thick limbs was either prevented (absent in regions A and $B$ of the inner stripe) or significantly reduced $(20 \pm 13 \%$ of tubules in region $C$ vs. $76 \pm 8 \%$ in filtering kidneys perfused

Table II. Multiple Regression Analysis of the Correlations between the Plasma Creatinine, the Proportion of $m T A L s$ with Collapse, and the Proportion of $m T A L s$ with Necrosis, All Obtained $24 \mathrm{~h}$ after the Acute Insult(s) from All Experimental Groups In Vivo

\begin{tabular}{lcccr}
\hline Variable & Slope & Partial $r$ & F-to-remove & $P$-value \\
\hline Necrosis & +3.04 & 0.89 & 101.2 & $<0.0001$ \\
Collapse & +0.35 & 0.19 & 4.6 & 0.0368 \\
Constant & 91.53 & & &
\end{tabular}

Dependent variable, plasma creatinine ( $\mu \mathrm{mol} / \mathrm{liter})$; predictor variables, proportion of mTALs with collapse, proportion of mTALs with necrosis (\%). Multiple $r=+0.84, \mathrm{~F}($ ANOVA) $=52.2, P$ $<0.0001$.

Table III. Contribution of Each Insult to Renal Injury Assessed by Discriminant Multivariate Analysis of All Experimental Groups In Vivo

\begin{tabular}{llcc}
\hline Dependent variable & Predictor variable & $\beta$ coefficient & $P$ value \\
\hline Plasma creatinine & Indomethacin & 78.8 & 0.0001 \\
& Salt depletion & 60.3 & 0.0013 \\
& Uninephrectomy & 58.0 & 0.0000 \\
& Contrast medium & 49.3 & 0.0096 \\
Proportion of mTALs & Indomethacin & 20.2 & 0.0005 \\
with necrosis & Contrast medium & 13.9 & 0.0155 \\
& Uninephrectomy & 13.3 & 0.0013 \\
& Salt depletion & 12.8 & 0.0207 \\
& & & \\
\hline
\end{tabular}

* Values 0 or 1 were used to define absence or presence of the insult (see Methods).

with iothalamate, $P<0.005$ ) and replaced by extensive tubular collapse. In the presence of ouabain, mTAL necrosis was also markedly reduced to $0,17 \pm 8$, and $16 \pm 6 \%$ in regions $A, B$, and $C$ respectively $(P<0.001)$. In all perfusions supplemented with blood (with and without indomethacin), mTAL necrosis was absent $(P<0.001)$. In the renal cortex, no significant changes were observed in the presence of iothalamate in comparison with control perfusions.

\section{Discussion}

The combination of salt depletion and indomethacin appeared to predispose rats to protracted renal dysfunction after the administration of contrast material. This finding confirms and extends similar observations in rabbits recently reported by Vari et al. (9). Uninephrectomy before these insults made the renal injury associated with ARF more consistent and more obvious.

The important new result of the present study is the association and correlation in vivo of severe ARF with a distinct and selective morphological injury to the mTALs. This lesion was similar in its nature to the damage regularly observed in isolated kidneys that had been perfused with cell-free medium and shown to derive from an imbalance between the relatively high oxygen demand (by the metabolically active mTALs) and the meager oxygen supply to the renal medulla (2). Thus, as in isolated kidneys, cell damage included mitochondrial swelling, nuclear pyknosis, and cytoplasmic disruption. As in perfused kidneys as well, this severe damage was selective for the mTALs, while elsewhere in the renal medulla or cortex, evidence for cell necrosis was generally absent. In addition, the injury to mTALs was located in the deepest regions of the inner stripe of the outer medulla and away from the vasa recta, thus in the zones most remote from oxygen supply. Furthermore, the extent of mTAL injury in vivo was inversely correlated with the extent of tubular collapse (associated with reduced solute delivery), which is in agreement with previous observations in the isolated perfused kidney where a decrease in transport activity (as in nonfiltering kidneys with extensive tubular collapse) prevents hypoxic damage to the mTAL (1, 19). This lesion to mTALs is hypothesized to be a hypoxic injury (1). It appears from these experiments that selective, putatively hypoxic injury to mTALs can be induced in vivo by 
Table IV. Renal Function of Isolated Kidneys Perfused with Contrast Medium or with Both Indomethacin and Contrast Medium, Compared with Control Perfusions

\begin{tabular}{|c|c|c|c|c|c|c|}
\hline & $\begin{array}{l}\text { Control perfusions } \\
\quad(n=10)\end{array}$ & $\begin{array}{l}\text { Perfusions with } \\
\text { iothalamate } \\
(n=10)\end{array}$ & $\begin{array}{l}\text { Perfusions with } \\
\text { indomethacin and } \\
\text { iothalamate } \\
(n=10)\end{array}$ & $\begin{array}{c}\text { Nonfiltering } \\
\text { kidneys with } \\
\text { iothalamate } \\
(n=6)\end{array}$ & $\begin{array}{l}\text { Perfusions with } \\
\text { ouabain and } \\
\text { iothalamate } \\
(n=4)\end{array}$ & $\begin{array}{l}\text { Perfusions with } \\
\text { erythrocytes } \\
\text { and iothalamate } \\
\qquad(n=6)\end{array}$ \\
\hline Renal perfusion flow ( $\mathrm{ml} / \mathrm{min}$ ) & $51.0 \pm 3.7$ & $36.3 \pm 3.5^{*}$ & $37.8 \pm 1.4^{*}$ & $45.3 \pm 2.5$ & $34.6 \pm 3.8^{*}$ & $11.2 \pm 3.0^{\ddagger}$ \\
\hline $\begin{array}{l}\text { Rapid changes in flow observed after } \\
\text { contrast (as \% of baseline) }\end{array}$ & $\begin{array}{l}\text { early } \\
\text { late }\end{array}$ & $\begin{array}{l}+18 \pm 4 \\
-15 \pm 2\end{array}$ & $\begin{array}{l}+27 \pm 5 \\
-25 \pm 5\end{array}$ & $\begin{array}{l}+10 \pm 3 \\
+2 \pm 1^{11}\end{array}$ & $\begin{array}{r}+46 \pm 6^{\prime \prime} \\
-1 \pm 4^{\prime \prime}\end{array}$ & $\begin{array}{r}63 \pm 16^{\prime \prime} \\
-25 \pm 10\end{array}$ \\
\hline $\begin{array}{l}\text { Tubular reabsorption of sodium } \\
\text { (as \% of filtered load) }\end{array}$ & $92.7 \pm 0.8$ & $83.2 \pm 2.0^{\ddagger}$ & $81.7 \pm 1.9^{\ddagger}$ & & $67.1 \pm 2.3^{\ddagger 11}$ & $73.4 \pm 3.5^{\ddagger}$ \\
\hline Glomerular filtration rate $(\mathrm{ml} / \mathrm{min})$ & $0.49 \pm 0.05$ & $0.36 \pm 0.06^{8}$ & $0.31 \pm 0.01^{*}$ & & $0.21 \pm 0.03^{*}$ & $0.36 \pm 0.06$ \\
\hline
\end{tabular}

Data are at $60 \mathrm{~min}$ of perfusion unless otherwise indicated. ${ }^{*} P<0.01 .{ }^{\ddagger} P<0.001 .{ }^{8} P<0.05$ vs. control perfusions. $" P<0.01$ vs. perfusions with iothalamate (in filtering kidneys).

a combination of multiple renal insults and that it is associated with ARF. Interestingly, medullary necrosis has been described in man after the administration of contrast (20). The paucity of similar observations may be related to the difficulty in obtaining medullary tissue at the appropriate time period and in recognizing $\mathrm{mTAL}$ injury in vivo (1).

The mTAL lesion did not occur immediately (i.e., it was not present at 70 or $80 \mathrm{~min}$ ) but was seen in a limited and focal fashion as early as $120 \mathrm{~min}$ after the acute insults. At $24 \mathrm{~h}$, the mTAL necrosis in the group subjected to UNK, SD, INDO, and $\mathrm{CM}$ was complicated by marked calcium and phosphorus (presumably $\mathrm{CaPO}_{4}$ ) deposition, which was demonstrated by electron probe analysis and was visible radiographically. This process may simply reflect the predilection of calcium to accumulate in necrotic material (21), although a catalytic role of calcium in this mTAL injury is not excluded.

An additional change was the vacuolar transformation of the early segments of the proximal tubule $\left(S_{1}\right.$ and $\left.S_{2}\right)$, which induced a picture that closely resembled what has been described in human contrast nephropathy and called osmotic nephrosis (22). Such changes are found in patients with severe chronic renal failure who have been given high doses of organic iodine and who developed acute episodes of renal functional impairment after injection (23). More limited changes of this type are found in patients with normal or impaired renal function who have been given low doses of iodine and who do not develop ARF after injection. These findings, however, are not sufficiently consistent to suggest that these proximal tubular changes are the basis of contrast nephropathy (24). Furthermore, Moreau et al. (24) observed that such changes could be elicited by isoosmolar media, which indicated the inappropriate use of the term osmotic nephrosis. These authors suggested that endocytotic mechanisms were the basis for the generation of these vacuolar changes. It is important to note that these investigators, as well as others, have never been able to produce, to our knowledge, such tubular changes with contrast media given to animals. Our findings suggest that the predominant origin of the vacuoles is not from an endocytotic mechanism but from invaginations of membranes of lateral cellular interdigitations. It seems possible that concentration of the highly lipid-soluble contrast media (25) in the paracellular zones might induce membrane injury with subsequent formation of these vesicular outpouchings.

In isolated perfused rat kidneys, the addition of contrast reproduced hemodynamic and functional changes (Table IV) reported in vivo $(17,18,26)$ and, especially when combined with indomethacin treatment, exacerbated the injury to the thick ascending limb. In nonfiltering kidneys, these effects were markedly attenuated, suggesting dependence on possible mediation by intraluminal presence of contrast material for this renal vasoconstrictive property, as proposed by others (26). The prevention of mTAL damage by the addition of erythrocytes to the perfusate supports a role for medullary hypoxia in the genesis of this injury (2). The increase in hypoxic mTAL damage induced by the radiocontrast agent is compatible with an adverse effect of contrast media upon the delicate balance of oxygen supply and demand within the renal medulla of isolated perfused kidneys $(1,2)$. Renal vasoconstriction probably reduced the delivery of oxygen to this site. At the same time, because of the osmotic diuresis, increased solute delivery to the mTAL might have enhanced active transport and oxygen consumption by this tubular segment.

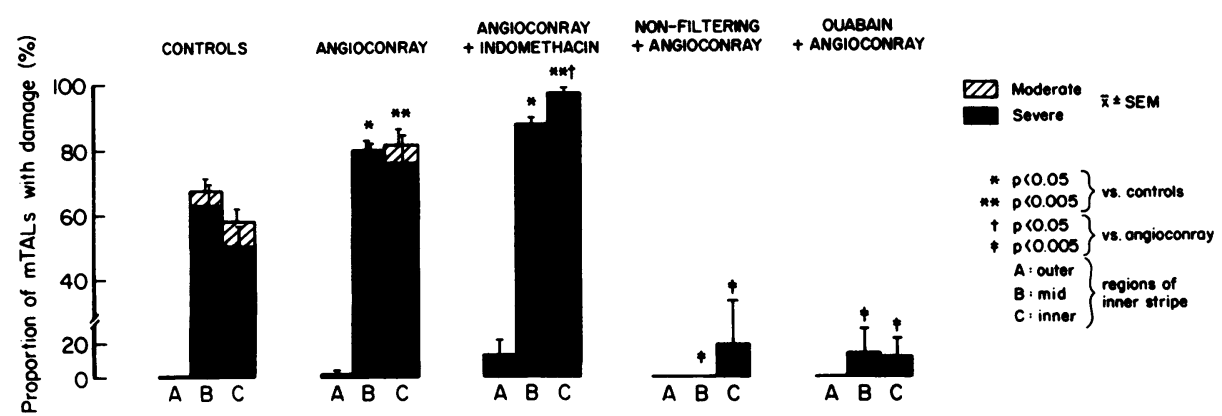

Figure 8. Proportions of mTAL tubules with damage in isolated kidneys perfused with iothalamate (Angio-Conray) or with indomethacin and iothalamate compared with control. Contrast-induced mTAL injury is almost completely abolished by the nonfiltering mode or inhibition of transport with ouabain. 
Inhibition of prostaglandin synthesis by indomethacin increased mTAL damage, conceivably inducing a further imbalance in medullary oxygenation as previously observed in this model (12), either by decreasing medullary flow or by increasing $\mathrm{mTAL}$ transport. The hemodynamic changes produced by contrast material resemble those induced by the administration of mannitol (26), which is known to stimulate prostaglandin excretion (27). Local release of prostaglandins may play an adaptive role to alleviate medullary hypoxia in the response of the kidney to the hyperosmotic contrast agent. Thus, the combination of medullary hypoxia (as induced by cell-free perfusion) with indomethacin treatment appears to be synergistic for the demonstration of a nephrotoxic effect of contrast material. Interestingly, other studies have previously suggested the existence of adverse interactions between renal hypoxia and contrast agents, which are possibly necessary for the development of experimental contrast nephrotoxicity (28-31).

Because of the morphological similarity in the nature and the distribution of the injury to mTAL between in vivo and in vitro experiments, one might speculate that the conditions producing ARF with mTAL necrosis in the whole animal (after salt depletion, indomethacin, and contrast) were, at least in part, reproducing the conditions present in the isolated perfused kidney (medullary hypoxia aggravated by indomethacin and contrast). In support of the need for salt depletion, rats prepared for exposure to salt depletion, indomethacin and contrast, but given dietary supplemental salt, had only a transient fall in renal function after indomethacin and contrast without mTAL injury (data not shown). Interestingly, the renal vasoconstrictive response to contrast is accentuated by sodium depletion by a mechanism possibly dependent upon the renin-angiotensin system (18). Preliminary experiments in rats suggest that the combination of angiotensin (by continuous infusion) with indomethacin and radiocontrast material also produces acute renal failure with selective necrosis of the mTALs (unpublished observations). In man, salt depletion and low cardiac output appear to be important risk factors for the development of ARF after the addition of contrast material $(10,32)$.

Reduction of the renal mass by uninephrectomy effectively enhanced the consistency and the severity of renal injury. Preliminary observations suggest that isolated perfused kidneys taken from rats with prior uninephrectomy have a more extensive hypoxic injury to the mTAL, which is associated with increased activity of the medullary Na-K-ATPase (14). After reduction of the renal mass, hyperfiltration of the remaining nephrons with an increased solute load for reabsorptive work may in itself be detrimental to the balance of oxygenation within the renal medulla, thereby diminishing the capacity of the mTAL to handle additional insults, such as indomethacin and contrast agent. In addition, the load of contrast material to be excreted per nephron was higher in uninephrectomized rats than in animals with two kidneys, perhaps contributing to increased toxicity. These observations may be relevant to the predisposition of patients with chronic renal failure to contrast nephrotoxicity $(6,7)$.

Animal models of ARF have traditionally used the application of one major renal insult (prolonged ischemia or toxins) for the convenient, predictable reproduction of experimental renal failure. In man, rather than single-causes, combinations of multiple renal insults or risk factors are increasingly incriminated before the onset of $\operatorname{ARF}(4,5)$. Although more difficult to study, combinations of several sublethal insults (such as gentamicin with endotoxemia) (33) used to increase the chances of significant renal dysfunction in the animal, may be somewhat closer to the phenomenon usually observed in man. Interestingly, in contrast to many other experimental models of ARF that have focused primarily on proximal tubular damage, the present model induced selective $\mathrm{MTAL}$ injury without necrosis in other portions of the nephron. Damage to mTALs has been reported in experimental renal ischemia, and sometimes in dissociation from injury to the pars recta $\left(S_{3}\right)$ of the proximal tubule $(1,3,34,35)$. Of particular interest is the fact that one model (cold ischemic preservation of transplanted rat kidneys) produced ARF associated with extensive destruction of the inner stripe of the outer medulla and only focal damage in $S_{3}(34,35)$. Conceivably, under some circumstances, the mTAL may become selectively injured in the inner stripe, perhaps because of higher metabolic requirements and/or lower oxygen tensions than in the outer stripe. The data presented here suggest a potential role for in vivo medullary hypoxia in the vulnerability of the kidney to combined insults that cause ARF. A combination of multiple risk factors, which presumably adversely affect the balance of oxygenation within the renal medulla, appears to be required to produce this syndrome.

In conclusion, the present study shows that multiple renal insults may be necessary to produce in the rat ARF that resembles the clinical syndrome of contrast nephropathy. Both in vivo and in vitro experiments suggest that the common pathway of renal injury in this model may be medullary hypoxia.

\section{Acknowledgments}

This work was supported by a grant (84-44) from the U.S.-Israel Binational Science Foundation, by the Fund for Basic Research administered by the Israel Academy of Sciences and Humanities, and by National Institutes of Health grants DK-18078 and RR-02604. Ms. Reubinoff received support from the Kornfeld Foundation.

\section{References}

1. Brezis, M., S. Rosen, P. Silva, and F. H. Epstein. 1984. Renal ischemia: a new perspective. Kidney Int. 26:375-383.

2. Brezis, M., S. Rosen, P. Silva, and F. H. Epstein. 1984. Selective vulnerability of the thick ascending limb to anoxia in the isolated perfused kidney. J. Clin. Invest. 73:182-189.

3. Kreisberg, J. I., R. E. Bulger, B. F. Trump, and R. B. Nagle. 1976. Effects of transient hypotension on the structure and function of the rat kidney. Virchows Arch. B Cell Pathol. 22:121-133.

4. Rasmussen, H. H., and L. S. Ibels. 1982. Acute renal failure. Multivariate analysis of causes and risk factors. Am. J. Med. 73:211218.

5. Shusterman, N., B. L. Strom, T. G. Murray, G. Morrison, S. L. West, and G. Maislin. 1987. Risk factors and outcome of hospital-acquired acute renal failure. Am. J. Med. 83:65-71.

6. Kjellstrand, C. M., R. O. Berkseth, and P. A. Abraham. 1984. Renal damage induced by radiologic contrast media. Nephrol. Proc. IXth Int. Congr. Nephrol. 835-843.

7. Misson, R. T., and R. E. Cutler. 1985. Radiocontrast-induced renal failure. West. J. Med. 142:657-664.

8. Taliercio, C. P., R. E. Vlietstra, L. D. Fisher, and J. C. Burnett. 1986. Risks for renal dysfunction with cardiac angiography. Ann. Intern. Med. 104:501-504.

9. Vari, R. C., L. A. Natarajan, S. A. Whitescarver, B. A. Jackson, and C. M. Ott. 1988. Induction prevention and mechanisms of contrast media induced acute renal failure. Kidney Int. 33:699-707. 
10. Kim, S. W., H. Na, C. H. Lee, C. G. Ihm, and H. B. Lee. 1983. The role of urinary sodium excretion in the radiocontrast-mediated acute renal failure. Proc. 16th Annu. Meeting Am. Soc. Nephrol., 95A

11. Clive, D. M., and J. S. Stoff. 1984. Renal syndromes associated with non-steroidal anti-inflammatory drugs. N. Engl. J. Med. 310:563-572.

12. Brezis, M., S. Rosen, J. F. Stoff, K. Spokes, P. Silva, and F. H. Epstein. 1986. Inhibition of prostaglandin synthesis in rat kidney perfused with and without erythrocytes: implication for analgesic nephropathy. Miner. Electrolyte Metab. 12:326-332.

13. Rubinger, D., Y. Frishberg, A. Eldor, and M. M. Popovtzer. 1985. The effect of suppression of prostaglandin synthesis on renal function in rats with intact and reduced renal mass. Prostaglandins. 30:651-668.

14. Spokes, K., S. Rosen, P. Silva, M. Brezis, and F. H. Epstein. 1986. Augmented vulnerability of renal medulla to injury produced by enhancement of Na-K-ATPase. Proc. 19th Annu. Meeting Am. Soc. Nephrol. 219A.

15. Brezis, M., P. Shanley, P. Silva, K. Spokes, S. Lear, F. H. Epstein, and S. Rosen. 1985. Disparate mechanisms for hypoxic cell injury in different nephron segments. Studies in the isolated perfused rat kidney. J. Clin. Invest. 76:1796-1806.

16. Ross, B. D., F. H. Epstein, and A. Leaf. 1973. Sodium reabsorption in the perfused rat kidney. Am. J. Physiol. 225:1165-1171.

17. Katzberg, R. W., T. W. Morris, F. A. Burgener, D. E. Kamm, and $\mathrm{H}$. W. Fischer. 1977. Renal renin and hemodynamic responses to selective renal artery catheterization and angiography. Invest. Radiol. 12:381-388.

18. Larson, T. S., K. Hudson, J. I. Mertz, J. C. Romero, and F. G. Know. 1983. Renal vasoconstrictive response to contrast medium. $J$. Lab. Clin. Med. 101:385-391.

19. Brezis, M., S. Rosen, K. Spokes, P. Silva, and F. H. Epstein. 1984. Transport-dependent anoxic cell injury in the isolated perfused rat kidney. Am. J. Pathol. 116:327-341.

20. Gilbert, E. F., G. H. Khoury, G. R. Hogan, and B. Jones. 1970. Hemorrhagic renal necrosis in infancy: relationship to radio-opaque compounds. J. Pediatr. 76:49-53.

21. Scarpelli, D. G., and M. Chiga. 1977. Cell injury and errors of metabolism. In Pathology. W. A. D. Anderson and J. M. Kissane, editors. C. V. Mosby Co., St. Louis. 120.

22. Allen, A. C. 1962. The kidney. Medical and Surgical Diseases, 2nd Ed. Grune and Stratton, Inc., New York. 207.

23. Moreau, J. F., D. Droz, J. Sabto, P. Jungers, D. Kleinknecht, N.
Hinglais, and J. R. Michel. 1975. Osmotic nephrosis induced by water-soluble triiodinated contrast media in man. A retrospective study of 47 cases. Radiology. 115:329-336.

24. Moreau, J. F., D. Droz, L. H. Noel, J. Leibowitch, P. Jungers, and J. R. Michel. 1980. Tubular nephrotoxicity of water-soluble iodinated contrast media. Invest. Radiol. 15(Suppl. 6):S54-60.

25. Rapoport, S. I., and H. Levitan. 1974. Neurotoxicity of x-ray contrast media. Relation to lipid solubility and blood-brain barrier permeability. Am. J. Roentgenol. Radium Ther. Nucl. Med. 122:186193.

26. Reed, J. R., R. H. Williams, and R. G. Luke. 1983. The renal hemodynamic response to diatrizoate in normal and diabetic rats. Invest. Radiol. 18:536-540.

27. Johnston, P. A., D. B. Bernard, N. S. Perrin, and N. G. Levinsky. 1981. Prostaglandins mediate the vasodilatory effect of mannitol in the hypoperfused rat kidney. J. Clin. Invest. 68:127-133.

28. Schultz, S. G., K. J. Lavelle, and R. Swain. 1982. Nephrotoxicity of radiocontrast media in ischemic renal failure in rabbits. Nephron. 32:113-117.

29. Lund, G., S. Einzig, J. Rysavy, B. Borgwardt, E. Salomonowitz, A. Cragg, and K. Amplatz. 1984. Role of ischemia in contrast-induced renal damage: an experimental study. Circulation. 69:783-789.

30. Rosenthal, A., S. B. Litwin, and M. B. Laver. 1973. Effect of contrast media used in angiocardiography on hemoglobin-oxygen equilibrium. Invest. Rádiol. 8:191-198.

31. Humes, H. D., D. A. Hunt, and M. D. White. 1987. Direct toxic effect of the radiocontrast agent diatrizoate on renal proximal tubule cells. Am. J. Physiol. 252:F246-255.

32. Taliercio, C. P., R. E. Vlietstra, L. D. Fisher, and J. C. Burnett. 1986. Risks for renal dysfunction with cardiac angiography. Ann. Intern. Med. 104:501-504.

33. Zager, R. A., and R. B. Prior. 1986. Gentamicin and gram-negative bacteria. A synergism for the development of experimental nephrotoxic acute renal failure. J. Clin. Invest. 78:196-204.

34. Harvig, B., A. Engberg, and J. L. E. Ericsson. 1980. Effects of cold ischemia on the preserved and transplanted rat kidney. Structural changes of the proximal tubule. Virchows Arch. B Cell Pathol. 34:153-171.

35. Harvig, B., A. Engberg, and J. L. E. Ericsson. 1980. Effects of cold ischemia on the preserved and transplanted rat kidney. Structural changes of the loop of Henle, distal tubule and collecting duct. Virchows Arch. B Cell Pathol. 34:173-192. 